\title{
Development of Ultrafine Grained Austenitic Stainless Steels by Large Strain Deformation and Annealing
}

Article in Materials Science Forum • May 2014

DOI: 10.4028/www.scientific.net/MSF.783-786.651

CITATION

1

5 authors, including:

Andrey Belyakov

Belgorod State University

181 PUBLICATIONS 2,526 CITATIONS

SEE PROFILE

Rustam Kaibyshev

Belgorod State University

417 PUBLICATIONS $\quad 4,367$ CITATIONS

SEE PROFILE
READS

24

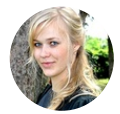

Odnobokova Marina

Belgorod State University

11 PUBLICATIONS 30 CITATIONS

SEE PROFILE

Some of the authors of this publication are also working on these related projects: 


\title{
Development of Ultrafine Grained Austenitic Stainless Steels by Large Strain Deformation and Annealing
}

\author{
Andrey Belyakov ${ }^{\mathrm{a}}$, Alla Kipelova ${ }^{\mathrm{b}}$, Marina Odnobokova ${ }^{\mathrm{c}}$, \\ laroslava Shakhova ${ }^{\mathrm{d}}$ and Rustam Kaibyshev ${ }^{\mathrm{e}}$
}

\author{
Belgorod State University, Pobeda 85, Belgorod 308015, Russia

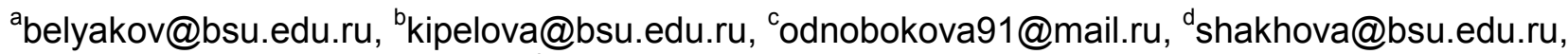 \\ erustam_kaibyshev@bsu.edu.ru
}

Keywords: austenitic stainless steels; cold rolling; grain refinement; phase transformations; recovery and recrystallization.

\begin{abstract}
The development of ultrafine grained structures in 316L and 304-type austenitic stainless steels subjected to large strain cold working and subsequent annealing and their effect on mechanical properties were studied. The cold rolling was accompanied by a mechanical twinning and a partial martensitic transformation and resulted in the development of elongated austenite/ferrite grains with the transverse size of about $50 \mathrm{~nm}$ at a strain of 4 . The grain refinement by large strain cold working resulted in an increase of tensile strength above $2000 \mathrm{MPa}$ in the both steels. Annealing at temperatures above $500^{\circ} \mathrm{C}$ resulted in ferrite-austenite reversion. However, the transverse grain/subgrain size remained on the level of about 100-150 nm after annealing at temperatures up to $700^{\circ} \mathrm{C}$.
\end{abstract}

\section{Introduction}

Ultrafine grained steels and alloys with a grain size below one micron are considered as advanced structural materials, which exhibit superior mechanical properties [1]. One of the most promising methods for the development of submicrocrystalline structures in various metallic materials is thermo-mechanical processing including large strain deformation [2]. The structural strengthening due to significant grain refinement is, especially, important for pseudo single phase austenitic stainless steels, which are commonly characterised by relatively low yield strength and high HallPetch response [3].

The strengthening by thermo-mechanical treatment depends on the size of grains/subgrains developed in the processed material. The grain/subgrain size evolved during deformation depends sensitively on deformation conditions, e.g. finer microstructure can be obtained by decreasing the deformation temperature [4]. On the other hand, the grain refinement kinetics slows down remarkably with decrease in deformation temperature. Austenitic stainless steels, however, are characterised by rather fast kinetic of grain refinement during cold working owing to their susceptibility to mechanical twinning and martensitic transformation $[5,6]$. The submicrocrystalline structures in such steels can be developed by conventional metal working processes without involvement of any specific techniques [6,7]. The aim of present paper is to introduce our current studies on the development of submicrocrystalline austenitic stainless steels by cold rolling and subsequent annealing.

\section{Experimental Procedure}

A 316L-type steel (Fe-0.04\%C-0.4\%Si-1.7\%Mn-17.3\%Cr-10.7\%Ni-2\%Mo-0.04\%P-0.05\%S) and an $\mathrm{S} 304 \mathrm{H}$-type steel $(\mathrm{Fe}-0.1 \% \mathrm{C}-0.12 \% \mathrm{~N}-0.1 \% \mathrm{Si}-0.95 \% \mathrm{Mn}-18.4 \% \mathrm{Cr}-7.95 \% \mathrm{Ni}-2.2 \% \mathrm{Cu}-0.5 \% \mathrm{Nb}-$ $0.01 \% \mathrm{P}-0.006 \% \mathrm{~S}$ ) were rolled at $700^{\circ} \mathrm{C}$ followed by annealing at $1100^{\circ} \mathrm{C}$ for $10 \mathrm{~min}$. Then, the calibre rolling was carried out to different strains up to 4 at room temperature. The cold rolled samples were cut into 70-mm specimens and annealed in a muffle furnace at various temperatures 
followed by water quenching. Structural investigations were performed on sections parallel to the rolling axis, using a JEM-2100 transmission electron microscope (TEM). The grain/subgrain sizes were measured perpendicular to the rolling axis by a linear intercept method. The dislocation densities were estimated by counting individual dislocations in grain/subgrain interiors in arbitrary selected TEM images. The tensile tests were carried out by using specimens with a gage length of about $8 \mathrm{~mm}$. Equilibrium volume fractions of the austenite were calculated with the software program ThermoCalc using a TCFE7 database.

\section{Results and Discussion}

Deformation Microstructures. Typical deformation structures developed in the austenitic stainless steels during cold rolling to a strain of 0.4 are shown in Fig. 1. Early deformation brings about high dislocation density, which exceeds $10^{15} \mathrm{~m}^{-2}$ after a strain of 0.4 . Following a rapid work hardening the deformation twinning starts to operate as a deformation mechanism concurrently with dislocation glide. An increase in the rolling strain is accompanied by the development of deformation microbands, which are composed of somewhat elongated austenite/ferrite grains with the transverse size of about $50 \mathrm{~nm}$ (Fig. 2). This suggests that deformation microbands as well as deformation twins $[5,6]$ are preferred nucleation sites for the strain-induced martensite. The misorientations at interphase boundaries in Fig. 2 indicate a mutual crystallographic rotation of $\alpha / \gamma$ cubes. The strain-induced martensite is characterised by rather large deviations from KurdjumovSachs (K-S) and Nishiyama-Wasserman (N-W) orientation relationship, although some $\alpha / \gamma$ boundaries exhibiting the misorientations of $46^{\circ}$ are close to the $\mathrm{N}-\mathrm{W}$ relationship.
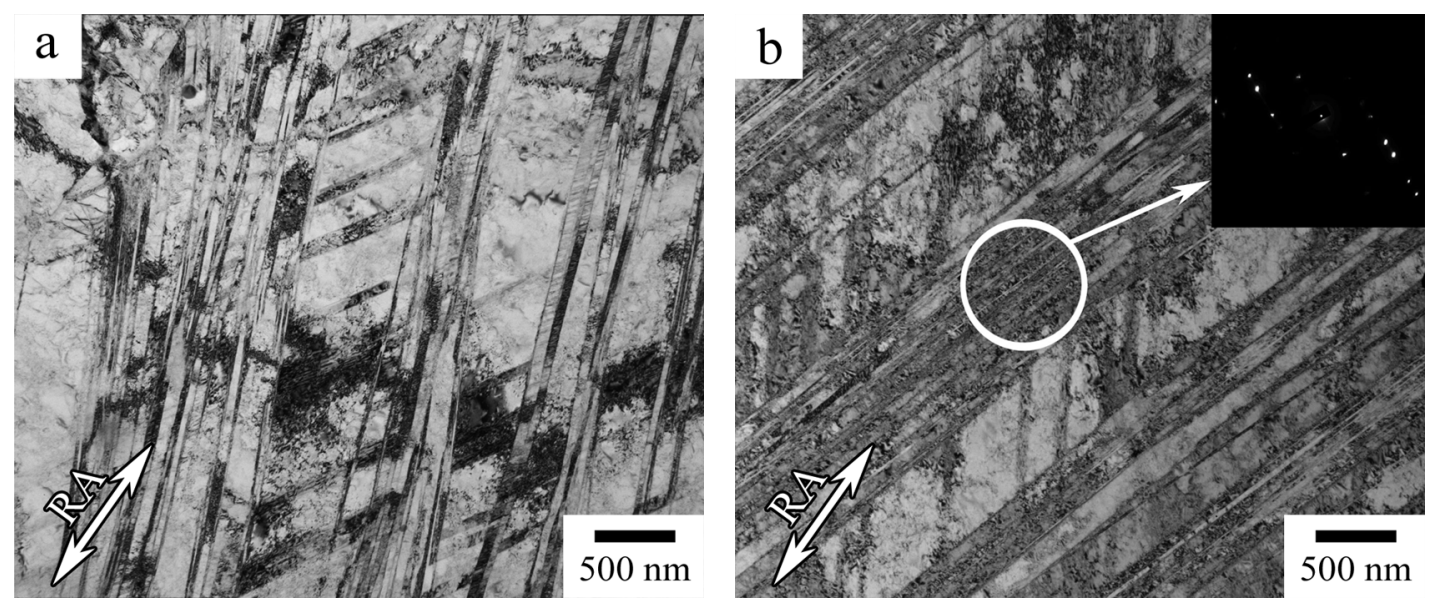

Fig. 1. Typical deformation microstructures developed in $\mathrm{S} 304 \mathrm{H}$ (a) and 316L (b) austenitic stainless steels after cold rolling to a strain of 0.4 . The RA indicates the rolling axis.

The austenite and martensite (or ferrite) grains/subgrains elongate toward the rolling axis during cold rolling to large strains, resulting in the development of lamellar microstructure consisting of an austenite/ferrite mixture with the mean transverse grain size of about $50 \mathrm{~nm}$ (Fig. 3). The longitudinal grain boundaries among ferrite lamellas are characterised by a wide variety of their angular misorientations from low-angle subboundaries to high-angle grain boundaries. Such a random character of boundary misorientations, especially in the range of $20-40^{\circ}$, suggests that the strain-induced ferrite (martensite) grains experience large rotations during the cold rolling and lose their original orientation relationships.

The strain effect on the deformation behaviour and microstructures of the S304H and 316L steels during the cold rolling is summarised in Fig. 4. A rapid twofold increase in the hardness of the both steels takes place during the rolling to a strain of 0.4 . Then, the rate of strain hardening decreases, leading to gradual increase in the hardness to about $5700 \mathrm{MPa}$ in the $\mathrm{S} 304 \mathrm{H}$ steel and $5000 \mathrm{MPa}$ in 
the 316L steel at a total strain of 4 . The structural changes are characterised by significant grain refinement assisted by the deformation twinning and strain-induced martensitic transformation. In the S304H steel, the $\gamma \rightarrow \alpha$ transformation develops more rapidly in the strain range of 1 to 2 , when the austenite fraction decreases from 0.8 to 0.55 ; further rolling to a strain of 4 results in a gradual decrease of the austenite fraction to approx. 0.35. In the 316L steel, the austenite is more stable against cold working; the $\gamma \rightarrow \alpha$ transformation readily develops at larger strains of 2 to 4 , leading to decrease in the austenite fraction from about 0.85 to 0.4 . The TermoCalc predicts the austenite fraction of about 0.15 in the both steels (the dotted line in Fig. 4).
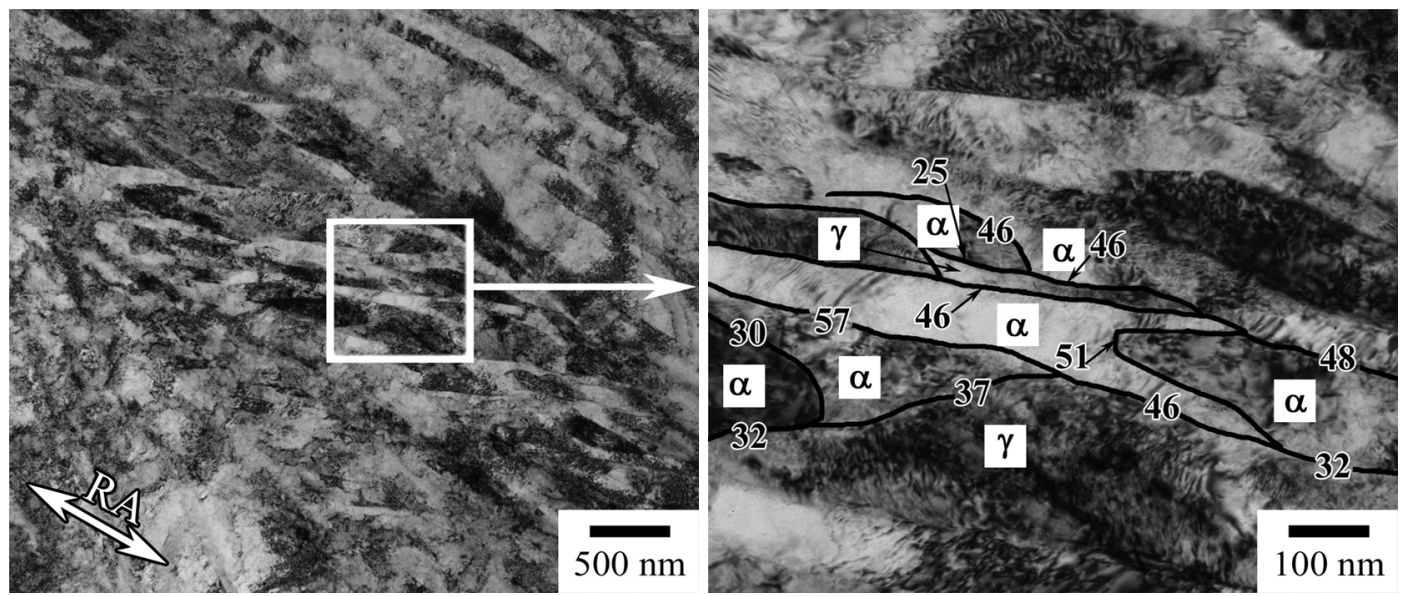

Fig. 2. Deformation bands and strain-induced martensite in a 316L steel cold rolled to a strain of 1.2. The numbers indicate the boundary misorientations in degrees.
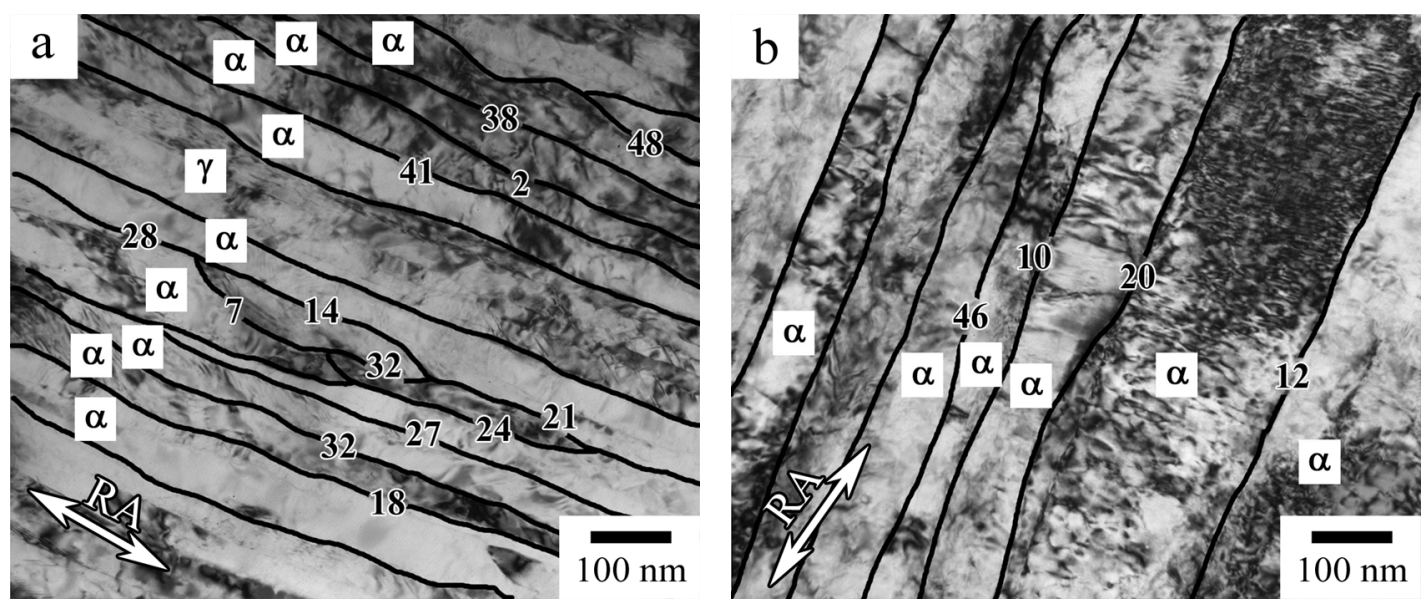

Fig. 3. Lamellar-type microstructure evolved in S304H (a) and 316L (b) steels after cold rolling to a strain of 4 .

Pronounced mechanical twinning promotes the fast grain subdivision in the both steels at relatively small strains (Fig. 4). The transverse grain/subgrain size decreases to about $60 \mathrm{~nm}$ upon cold rolling to a strain of 1 . Subsequent processing does not result in a remarkable change in the grain/subgrain size, which approach about $50 \mathrm{~nm}$ at a strain of 4 . The grain refinement during the cold rolling is accompanied by a drastic increase in the dislocation density in grain/subgrain interiors. The rapid increase in the dislocation density occurs in the strain ranges of 1-2 for the $\mathrm{S} 304 \mathrm{H}$ steel and 2-4 for the 316L steel. It is worth noting that the fastest kinetics of the $\gamma \rightarrow \alpha$ transformations was observed in the same strain ranges. 

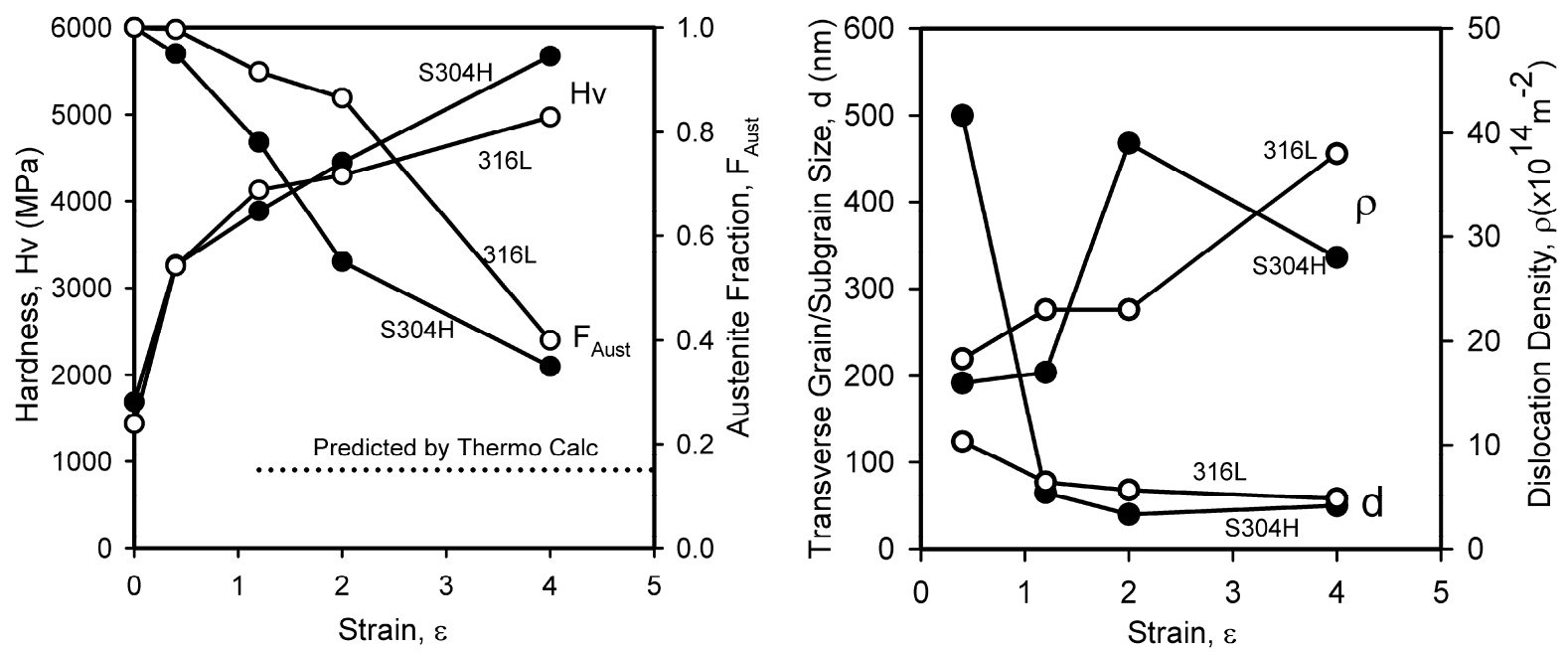

Fig. 4. Effect of cold rolling on the hardness, the austenite fraction, the transverse grain/subgrain size, and the dislocation density in $\mathrm{S} 304 \mathrm{H}$ and $316 \mathrm{~L}$ austenitic stainless steels.
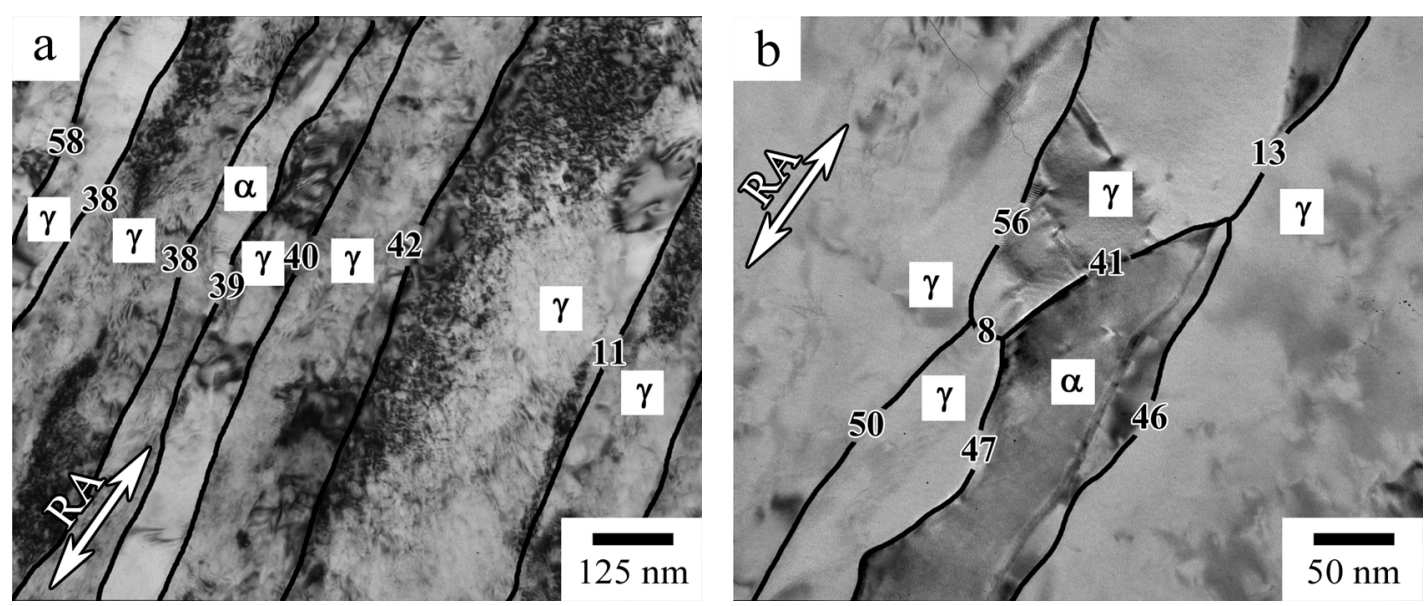

Fig. 5. Annealed microstructures developed in a 316L austenitic stainless steel, which was cold rolled to a total strain of 4 and then annealed for $30 \mathrm{~min}$ at $500^{\circ} \mathrm{C}$ (a) and $600^{\circ} \mathrm{C} \mathrm{(b).}$

Annealed Microstructures. Annealing at temperatures below $500^{\circ} \mathrm{C}$ does not result in remarkable changes of the deformation microstructures in the both steels. An example of the microstructure annealed at $500^{\circ} \mathrm{C}$ for $30 \mathrm{~min}$ is shown in Fig. 5a. This annealed microstructure looks like the cold rolled one consisting of highly elongated austenite/ferrite grains with an almost random grain boundary misorientation distribution and high dislocation density in grain/subgrain interiors. An increase of the annealing temperature above $500^{\circ} \mathrm{C}$ results in the $\alpha \rightarrow \gamma$ reversion accompanied with a little grain/subgrain growth and a decrease in the dislocation density. The $\alpha \rightarrow \gamma$ reversion develops with a small deviation from ideal K-S and/or N-W orientation relationships (Fig. $5 b)$. It should be noted that the annealed microstructures retain their lamellar-type morphology involved by unidirectional cold rolling irrespective of phase transformation and grain growth.

The temperature effect on the softening and structural changes in $\mathrm{S} 304 \mathrm{H}$ and $316 \mathrm{~L}$ steels subjected to isochronal annealing for $30 \mathrm{~min}$ is summarised in Fig. 6. The both steels are characterised by almost the same softening behaviour during annealing. The hardness of cold rolled $\mathrm{S} 304 \mathrm{H}$ and $316 \mathrm{~L}$ steel samples gradually decreases to about $3000 \mathrm{MPa}$ with increasing the annealing temperature to $800^{\circ} \mathrm{C}$. According to TermoCalc calculations (the dotted lines in Fig. 6) the $\alpha \rightarrow \gamma$ transformation should be expected in the temperature range of $500-700^{\circ} \mathrm{C}$; and the faster 
austenite reversion is expected in $316 \mathrm{~L}$ steel as compared to $\mathrm{S} 304 \mathrm{H}$ one. The experimental data for austenite fraction in the annealed samples follow qualitatively the predicted transformation behaviour, although the measured austenite fractions are somewhat larger than predicted by ThermoCalc at $500-600^{\circ} \mathrm{C}$. This can be associated with an additional driving force for phase transformation, which was exerted by large strain deformation [8]. Numerous nucleation sites for the austenite reversion in the submicrocrystalline structures, which were developed by large strain deformation, allow us to obtain ultrafine grained steels with the transverse grain size of 100-150 nm even after annealing at an elevated temperature of $700^{\circ} \mathrm{C}$ (Fig. 6).
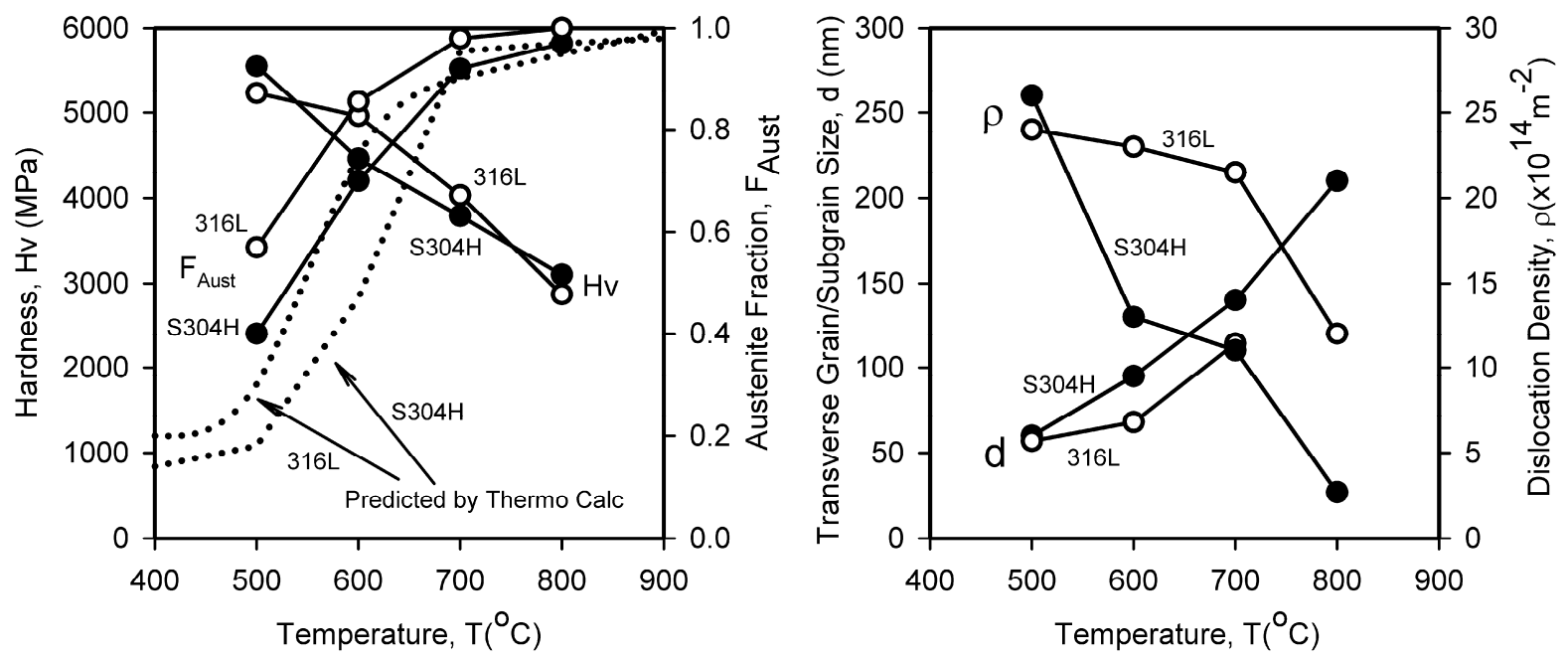

Fig. 6. Effect of annealing temperature on the hardness, the austenite fraction, the transverse grain/subgrain size, and the dislocation density in $\mathrm{S} 304 \mathrm{H}$ and $316 \mathrm{~L}$ austenitic stainless steels.

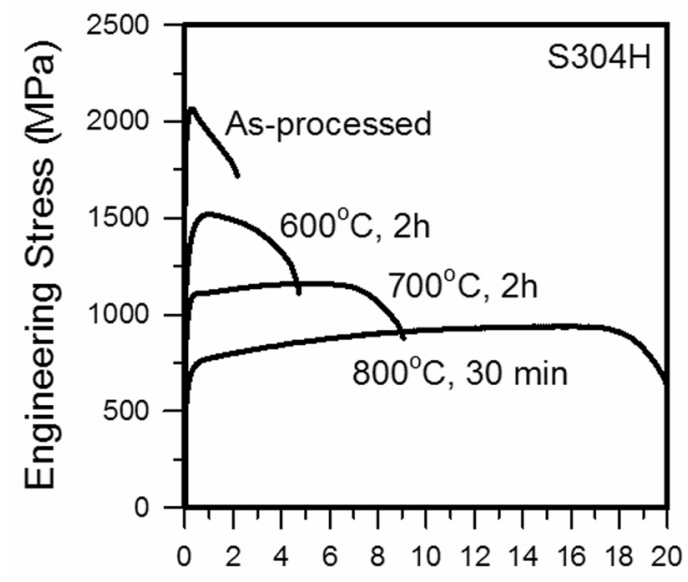

Engineering Strain (\%)

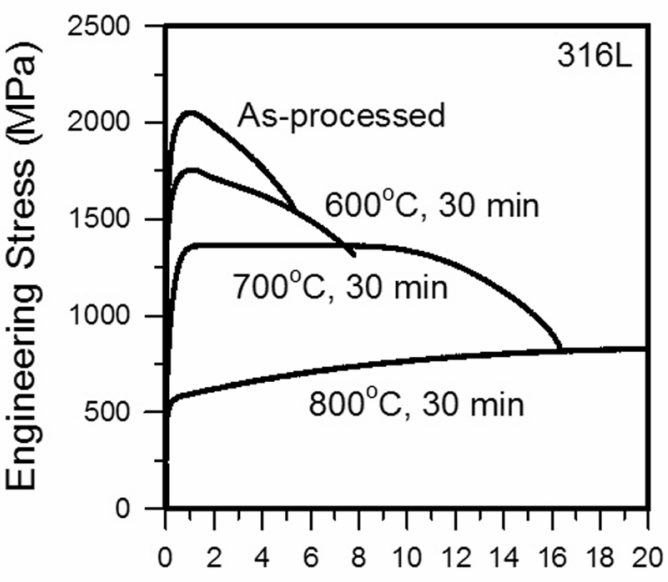

Engineering Strain (\%)

Fig. 7. The tensile stress-strain curves for $\mathrm{S} 304 \mathrm{H}$ and $316 \mathrm{~L}$ steels subjected to cold rolling to a strain of 4 and then annealed under the indicated conditions.

Tensile Behaviour. A series of tensile stress-strain curves for the ultrafine grained stainless steels subjected to large strain cold rolling and subsequent annealing are shown in Fig. 7. The cold rolling to a total strain of 4 results in a high tensile strength of above $2000 \mathrm{MPa}$ in the studied steels. On the other hand, the cold rolled steels are characterised by a quite low plasticity; the uniform elongation does not exceed $1 \%$. Commonly, plasticity of work hardened metals and alloys can be improved by a subsequent heat treatment. The data in Fig. 7 suggest that rather large uniform elongation of $6-8 \%$ in the processed steels can be obtained by an annealing at $700^{\circ} \mathrm{C}$. In this case the 
improved plasticity is combined with a high tensile strength of well above $1000 \mathrm{MPa}$. It should be noted that the cold rolled and annealed 316L steel exhibit larger tensile elongations than the $\mathrm{S} 304 \mathrm{H}$ one. This difference can be attributed to the different austenite stability in these steels and, therefore, larger austenite fractions in the $316 \mathrm{~L}$ steel.

\section{Summary}

The cold rolling of S304H and 316L-type steels is accompanied by a mechanical twinning and a partial martensitic transformation and results in the development of lamellar-type microstructure consisting of highly elongated austenite/ferrite grains. The transverse size of grains/subgrains evolved in large strains is about $50 \mathrm{~nm}$. The grain refinement by large strain cold working results in increase of the tensile strength above $2000 \mathrm{MPa}$ and a significant degradation of ductility in the both steels. Annealing at temperatures below $500^{\circ} \mathrm{C}$ did not lead to any remarkable changes in the deformation microstructures, whereas increase in the annealing temperature leads to ferrite-austenite reversion. However, the transverse grain/subgrain size remains on the level of about 100-150 nm after annealing at temperatures up to $700^{\circ} \mathrm{C}$. Correspondingly, these samples exhibit a high tensile strength above $1000 \mathrm{MPa}$ with a uniform elongation of $6-8 \%$. The $316 \mathrm{~L}$ steel is characterized by a better combination of strength and plasticity as compared to the $\mathrm{S} 304 \mathrm{H}$ one.

\section{Acknowledgements}

The financial support received from the Ministry of Education and Science, Russia, under grant No. 14.A18.21.1844 is gratefully acknowledged. The authors are grateful to personnel of the Joint Research Centre, Belgorod State University, for their assistance with instrumental analysis.

\section{References}

[1] R.Z. Valiev, T.G. Langdon, The art and science of tailoring materials by nanostructuring for advanced properties using SPD techniques, Adv. Eng. Mater. 12 (2010) 677-691.

[2] Y. Estrin, A. Vinogradov, Extreme grain refinement by severe plastic deformation: a wealth of challenging science, Acta Mater. 61 (2013) 782-817.

[3] Z. Yanushkevich, A. Mogucheva, M. Tikhonova, A. Belyakov, R. Kaibyshev, Structural strengthening of an austenitic stainless steel subjected to warm-to-hot working, Mater. Character. 62 (2011) 432-437.

[4] A.N. Belyakov, Changes in grain structure of metallic materials upon plastic treatment, Phys. Met. Metallogr. 108 (2009) 390-400.

[5] N. Nakada, H. Ito, Y. Matsuoka, T. Tsuchiyama, S. Takaki, Deformation-induced martensitic transformation behaviour in cold-rolled and cold-drawn type 316 stainless steels, Acta Mater. 58 (2010) 895-903.

[6] I. Shakhova, V. Dudko, A. Belyakov, K. Tsuzaki, R. Kaibyshev, Effect of large strain cold rolling and subsequent annealing on microstructure and mechanical properties of an austenitic stainless steel, Mater. Sci. Eng. A 545 (2012) 176-186.

[7] M. Eskandari, A. Zarei-Hanzaki, H.R. Abedi, An investigation into the room temperature mechanical properties of nanocrystalline austenitic stainless steels, Mater. Design 45 (2013) 674-681.

[8] B.B. Straumal, A.A. Mazilkin, B. Baretzky, G. Schutz, E. Rabkin, R. Valiev, Accelerated diffusion and phase transformations in $\mathrm{Co}-\mathrm{Cu}$ alloys driven by the severe plastic deformation, Mater. Trans. 53 (2012) 63-71. 